\title{
Dynamics of methanogenesis, ruminal fermentation and fiber digestibility in ruminants following elimination of protozoa: a meta-analysis
}

\author{
Zongjun Li ${ }^{1}$, Qi Deng ${ }^{1,2}$, Yangfan Liu', Tao Yan ${ }^{1}$, Fei Li ${ }^{1,3}$, Yangchun Cao ${ }^{1}$ and Junhu Yao ${ }^{1 *}$ (D
}

\begin{abstract}
Background: Ruminal microbes are vital to the conversion of lignocellulose-rich plant materials into nutrients for ruminants. Although protozoa play a key role in linking ruminal microbial networks, the contribution of protozoa to rumen fermentation remains controversial; therefore, this meta-analysis was conducted to quantitatively summarize the temporal dynamics of methanogenesis, ruminal volatile fatty acid (VFA) profiles and dietary fiber digestibility in ruminants following the elimination of protozoa (also termed defaunation). A total of 49 studies from 22 publications were evaluated.

Results: The results revealed that defaunation reduced methane production and shifted ruminal VFA profiles to consist of more propionate and less acetate and butyrate, but with a reduced total VFA concentration and decreased dietary fiber digestibility. However, these effects were diminished linearly, at different rates, with time during the first few weeks after defaunation, and eventually reached relative stability. The acetate to propionate ratio and methane production were increased at 7 and 11 wk after defaunation, respectively.
\end{abstract}

Conclusions: Elimination of protozoa initially shifted the rumen fermentation toward the production of more propionate and less methane, but eventually toward the production of less propionate and more methane over time.

Keywords: Defaunation, Fiber digestibility, Meta-analysis, Methane production, Rumen fermentation

\section{Introduction}

The rumen provides an ideal habitat for protozoa, whose concentration can reach $10^{5}-10^{6}$ cells $/ \mathrm{mL}$. In return, protozoa serve important functions in the rumen microbial ecosystem, such as predation, competition for nutrients, and involvement in symbiotic relationships with other microorganisms $[1,2]$. Protozoa prey on bacteria and fungal spores, but are preferentially retained in the rumen, thus reducing the postruminal microbial protein supply [3]. Protozoa compete with amylolytic bacteria for dietary starch, which is mostly fermented into acetate by protozoa [2] while mostly into propionate by amylolytic bacteria [3, 4]. For host animals, the energy

\footnotetext{
* Correspondence: yaojunhu2004@sohu.com

${ }^{1}$ College of Animal Science and Technology, Northwest A\&F University,

Yangling, Shaanxi, China

Full list of author information is available at the end of the article
}

recovery efficiency is reduced by $38 \%$ when the substrate (glucose) is fermented into acetate but increased by $9 \%$ when fermented into propionate [3, 4]. Protozoa are important ruminal hydrogen $\left(\mathrm{H}_{2}\right)$ producers, and the produced $\mathrm{H}_{2}$ is mostly converted into methane $\left(\mathrm{CH}_{4}\right)$ by methanogens situated inside protozoa or on their external surface [5-7]. The $\mathrm{CH}_{4}$ emissions from ruminants represent $2-12 \%$ dietary energy loss [8]. Therefore, the presence of protozoa seems to adversely affect animals' energy efficiency.

Complete removal of ruminal protozoa, termed defaunation, has been suggested as an efficient method for reducing $\mathrm{CH}_{4}$ emissions and enhancing propionate fermentation $[9,10]$, but these effects have not been consistently observed in studies investigating this 112method [11-13]. Hegarty et al. [12] and Morgavi et al. [13] suggested that the duration of defaunation might be 
responsible for this inconsistency, but the temporal dynamics of methanogenesis and ruminal volatile fatty acid (VFA) profiles after defaunation are difficult to determine experimentally because of the difficulties in raising defaunated animals over a long-term [14]. Meta-analysis is a statistical method that combines the results from multiple studies to achieve a more precise estimate of treatment effects and to explore the potential sources of between-study heterogeneity $[15,16]$. Two prior meta-analyses $[14,17]$ have summarized the combined responses of rumen fermentation to defaunation; however, the combined effects on ruminal VFA profiles were also inconsistent between them, and neither of them explored the time-dependent effects. Therefore, the current meta-analysis was conducted to quantitatively summarize the temporal dynamics of methanogenesis, ruminal VFA profiles and dietary fiber digestibility in ruminants after defaunation, and to explain the contribution of the defaunated duration to the between-study heterogeneity.

\section{Methods}

Literature search, screening and data extraction

A flowchart detailing the process of literature search, screening and data extraction is shown in Fig. 1. The inclusion criteria for the studies were as follows: (1) peer-reviewed and published in the English language; (2) complete defaunation in vivo; (3) inclusion of relevant variables for extraction. The relevant variables for this meta-analysis included the daily $\mathrm{CH}_{4}$ production, ruminal VFA profiles and dietary fiber total-tract digestibility.

The faunation states of control animals included the natural ruminal ecosystem without any treatment or reintroduction of protozoa after partial defaunation, which appeared to be restored quickly after withdrawal of the protozoa-inhibiting treatment $[18,19]$. The control animals into which protozoa were reintroduced after complete defaunation were excluded from the analysis, because preliminary analysis showed that high heterogeneity existed between the faunation and refaunation subgroups (see Additional file 1). Protozoa-free animals were obtained through either the absence of protozoa from birth (BF) or artificial removal of protozoa from the natural ruminal ecosystem (AF). Artificial defaunation was conducted using chemical agents, such as alkanes and sodium lauryl sulfate, or by applying a rumen washing technique. The defaunation duration was calculated based on the schedule of experimental activities. The defaunation duration of $\mathrm{BF}$ animals was calculated as their age shortened by $4 \mathrm{wk}$, because ruminal protozoa did not appear when newborn calves were fed with milk for $30 \mathrm{~d}$ [2], and the concentration of protozoa quickly increased after $5 \mathrm{wk}$ of age [20].

The final database included 22 publications, with 49 in vivo studies that satisfied the inclusion criteria for the

238 papers potentially relevant studies identified from the scientific electronic databases and citations in review papers

169 excluded on the basic of publication type

With 45 books, review papers and meeting abstracts

With 43 in vitro studies

With 81 non-relevant records

47 excluded on the basic of experimental designs

With 12 partial defaunation

With 20 reintroduced protozoa after complete defaunation

With 15 lack of statistical information

22 papers with 49 trials satisfied the inclusion criteria for meta-analysis

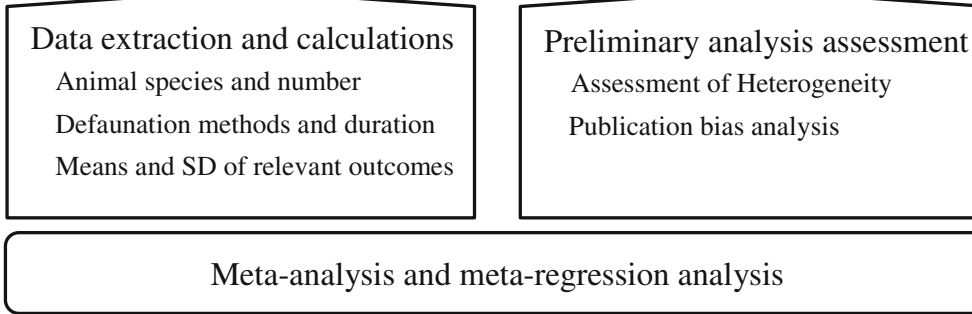

Fig. 1 Flow chart of the literature search, screening and data extraction procedures 
meta-analysis. Summary descriptions of the selected studies are provided in Table 1 . Briefly, among the 49 selected studies, 38 were conducted in sheep, and 11 were conducted in cattle; 18 measured $\mathrm{CH}_{4}$ production, 29 measured ruminal VFAs, and 15 measured total-tract fiber digestibility. $\mathrm{CH}_{4}$ emissions were measured using the respiration chamber technique or sulfur hexafluoride tracer technique. Methane production was presented in liters per day in most of the studies; thus, values presented in grams or kilojoules (kJ) were converted to liters per day, based on the assumption that one mole of $\mathrm{CH}_{4}$ weighs $16 \mathrm{~g}$ or contains $890 \mathrm{~kJ}$ of energy and occupies a volume of $24.5 \mathrm{~L}$ (under conditions of $25{ }^{\circ} \mathrm{C}$ and 1 atmospheric pressure).

\section{Data analysis}

The meta-analysis was performed using Stata 14.1 (Stata Corp., Texas, USA).

\section{Assessment of heterogeneity and effect size}

Between-study variability was quantified via the $I^{2}$ statistic, which measures the percentage of variation due to heterogeneity $[15,21]$. When the $I^{2}$ value was less than $50 \%$, indicating low heterogeneity, studies were combined using a fixed effects model, which was based on the assumption that the expected effect from each study was homogeneous. When the value of $I^{2}$ was over 50\%, indicating high heterogeneity, studies were combined using a random effects model, based on the assumption that the expected effect from each study was heterogeneous.

The differences in animal species or ages, daily sampling times or dietary forage percentages across the studies caused that the data of certain relevant variables to vary greatly across the studies (Table 2). To reduce these potential interferences, the effect size in this analysis was estimated via the standardized mean difference (SMD), which was calculated as the raw mean difference between the treatment and control groups divided by their pooled standard deviations [15]. For example, although cattle $\mathrm{CH}_{4}$ production in the study by Schönhusen et al. [20] was higher than in other subgroup studies involving sheep, it was homogeneous with most of them (Additional file 1: Figures S1 and S2). The studies were weighted using the inverse of the variance of the differences in means. Details of the calculations used in the meta-analysis are provided by Lean et al. [15].

\section{Meta-regression analysis}

The meta-regression analysis was performed using the Knapp-Hartung restricted maximum likelihood method [22], with the SMD of the individual studies used as the response variable and the corresponding standard error

Table 1 Data sources and characteristics of the studies included in the meta-analysis

\begin{tabular}{|c|c|c|c|c|}
\hline Source & Trials & Animal & Defaunation duration & Outcomes \\
\hline Belanche et al. [44] & 2 & Sheep & $23 w k$ & VFA, digestibility \\
\hline Bird et al. [11] & 2 & Sheep & $11,26 w k$ & $\mathrm{CH}_{4}, \mathrm{VFA}$, digestibility \\
\hline Chandramoni et al. [45] & 2 & Sheep & $5,11 \mathrm{wk}$ & $\mathrm{CH}_{4}$, digestibility \\
\hline Chaudhary and Srivastava [46] & 2 & Cattle & $18 w k$ & Digestibility \\
\hline Eadie and Gill [47] & 2 & Sheep & 22,55 wk & VFA \\
\hline Eugène et al. [48] & 4 & Sheep & $10,14,18,22 \mathrm{wk}$ & Digestibility \\
\hline Frumholtz [38] & 3 & Sheep & $5,26,52 \mathrm{wk}$ & VFA \\
\hline Hegarty et al. [12] & 4 & Sheep & $12,22,24,33 \mathrm{wk}$ & $\mathrm{CH}_{4}, \mathrm{VFA}$ \\
\hline Kasuya et al. [49] & 1 & Cattle & $21 w k$ & Digestibility \\
\hline Kreuzer et al. [50] & 3 & Sheep & $9,10,11 \mathrm{wk}$ & $\mathrm{CH}_{4}$ \\
\hline Morgavi et al. [13] & 2 & Sheep & $6 w k, 2 y r$ & $\mathrm{CH}_{4}, \mathrm{VFA}$ \\
\hline Nagaraja et al. [51] & 2 & Sheep & 14 wk & VFA \\
\hline Nguyen et al. [33] & 2 & Sheep & 9 wk & $\mathrm{CH}_{4}$, VFA, digestibility \\
\hline Ozutsumi et al. [35] & 1 & Cattle & 14 wk & VFA \\
\hline Santra and Karim [52] & 2 & Sheep & $12 \mathrm{wk}$ & Digestibility \\
\hline Santra and Karim [53] & 3 & Sheep & $14 \mathrm{wk}$ & Digestibility \\
\hline Santra et al. [54] & 2 & Sheep & $8 w k$ & Digestibility \\
\hline Schönhusen et al. [20] & 4 & Cattle & $4,5,6,7 \mathrm{wk}$ & $\mathrm{CH}_{4}, \mathrm{VFA}$, digestibility \\
\hline Sultana et al. [55] & 1 & Cattle & 14 wk & VFA \\
\hline Williams and Dinusson [56] & 2 & Cattle & 30,56 wk & VFA \\
\hline Yáñez-Ruiz et al. [57] & 1 & Sheep & $18 w k$ & VFA \\
\hline Zhou et al. [58] & 2 & Sheep & 5 wk & $\mathrm{CH}_{4}, \mathrm{VFA}$ \\
\hline
\end{tabular}


Table 2 Data summary and meta-analysis of relevant variables based on all of the selected studies

\begin{tabular}{|c|c|c|c|c|c|c|c|c|c|c|}
\hline \multirow[t]{2}{*}{ Variables } & \multirow{2}{*}{$\begin{array}{l}\text { No. } \\
\text { of } \\
\text { trials }\end{array}$} & \multicolumn{3}{|c|}{ Defaunation group } & \multicolumn{3}{|c|}{ Faunation group } & \multicolumn{3}{|c|}{ Meta-analysis } \\
\hline & & $\bar{n}$ & Mean & SD & $\bar{n}$ & Mean & SD & $R, \%$ & SMD & $P$-value \\
\hline $\mathrm{CH}_{4}, \mathrm{~L} / \mathrm{d}$ & 18 & 126 & 20.8 & 12.4 & 129 & 23.4 & 12.0 & 71.9 & -0.602 & 0.037 \\
\hline Total VFA, mmol/L & 29 & 211 & 78.8 & 29.7 & 212 & 87.1 & 31.3 & 44.2 & -0.549 & $<0.001$ \\
\hline \multicolumn{11}{|c|}{ Individual VFA molar proportion, \% } \\
\hline Acetate & 29 & 210 & 67.7 & 5.6 & 211 & 66.3 & 4.3 & 67.8 & 0.358 & 0.083 \\
\hline Propionate & 29 & 210 & 21.0 & 4.8 & 211 & 20.6 & 3.1 & 73.5 & 0.150 & 0.515 \\
\hline Butyrate & 27 & 202 & 8.2 & 2.0 & 203 & 10.2 & 2.8 & 68.3 & -1.026 & $<0.001$ \\
\hline$A: P$ & 18 & 78 & 3.6 & 1.6 & 81 & 3.5 & 0.7 & 77.0 & -0.284 & 0.493 \\
\hline \multicolumn{11}{|c|}{ Total-tract fiber digestibility, \% } \\
\hline NDF & 15 & 109 & 55.0 & 11.6 & 109 & 58.1 & 11.8 & 55.7 & -2.063 & $<0.001$ \\
\hline ADF & 11 & 82 & 42.8 & 2.7 & 82 & 45.7 & 3.7 & 69.8 & -3.075 & $<0.001$ \\
\hline
\end{tabular}

$n$ number of animals, $I^{2}$ percentage of heterogeneity across studies, SMD standardized mean difference, $A: P$ acetate: propionate ratio, NDF neutral detergent fiber, $A D F$ acid detergent fiber

of the SMD used as the variance. The percentage of between-study heterogeneity explained by the covariate (defaunation duration) was quantified via the adjusted $R^{2}$ value.

Preliminary analysis showed that the temporal SMD dynamics after defaunation included a linear phase followed by a plateau phase. The durations of the linear phase and plateau phase for each outcome were dependent on the highest adjusted $R^{2}$ of the meta-regression analysis and the minimum $I^{2}$ of the heterogeneity analysis, respectively; therefore, the two phases might overlap over a short duration. The probability levels were set at $P<0.05$ for significance and $0.05 \leq P<0.10$ for a trend.

\section{Results}

\section{Effect size and heterogeneity across all the studies}

The meta-analysis based on all the selected studies showed that elimination of rumen protozoa reduced $(P$ $<0.05) \mathrm{CH}_{4}$ production, ruminal VFA concentration, the proportion of butyrate and dietary fiber digestibility, and tended to increase $(P=0.083)$ the proportion of acetate (Table 2). However, the heterogeneity across the studies was considerable $\left(I^{2}>50 \%\right)$ for most of the responses to defaunation, except for the ruminal VFA concentration $\left(I^{2}=44.2 \%\right)$.

\section{Methanogenesis dynamics during adaptation to defaunation}

Compared with that of faunation, the effect size of defaunation on $\mathrm{CH}_{4}$ emissions presented a linear relationship over time during the first $12 \mathrm{wk}$ (linear phase) after defaunation (Fig. 2 and Table 3): $\mathrm{CH}_{4}$ production was reduced by defaunation (intercept $=-5.484, P=$ $0.003)$, and the reduction decreased weekly by $0.486(P$ $=0.003$ ) until $12 \mathrm{wk}$. The defaunation duration explained
$76.8 \%$ of the between-study heterogeneity $\left(I^{2}=76.2 \%\right)$ during the linear phase, and no between-study heterogeneity $\left(I^{2}=0.0 \%\right)$ was observed after 11 wk (plateau phase), suggesting that little fluctuation occurred during the plateau phase. Interestingly, the defaunated animals during the plateau phase presented higher $\mathrm{CH}_{4}$ productions $(\mathrm{SMD}=0.313, P=0.039)$ than the control animals.

\section{Ruminal VFA profiles and total-tract fiber digestibility dynamics during adaptation to defaunation}

Consistent with the temporal dynamics of $\mathrm{CH}_{4}$ production after defaunation, the ruminal VFA profiles dynamics also included a linear phase $(\leq 11 \mathrm{wk})$ and a plateau phase ( $\geq 7 \mathrm{wk}$ ) (Table 3). After defaunation, decreases in the acetate proportion, butyrate proportion and A:P (intercept $=-4.086,-7.059$ and -6.737 , respectively), and an increase in the propionate proportion (intercept $=7.306)$ were estimated $(P<0.01)$. These alterations decreased linearly $(P<0.01)$ at different rates over the first 11 wk of defaunation; instead, the ruminal acetate proportion $(\mathrm{SMD}=0.748, P<0.001)$ and $\mathrm{A}: \mathrm{P}(\mathrm{SMD}=0.915$, $P=0.016)$ were higher, and the propionate proportion (SMD $=-0.366, P=0.033)$ was lower in defaunated animals than faunated animals during the plateau phase.

Compared with faunated animals, defaunated animals exhibited a reduced total VFA concentration (intercept $=-1.883$ and $P=0.008)$, and the reduction decreased weekly by $0.132(P=0.048)$ until 12 wk (Table 3$)$. The duration of defaunation could explain $99.9 \%$ of the between-study heterogeneity during the linear phase, although the heterogeneity (35.5\%) was low. The decrease in total VFA concentration was still observed (SMD = $0.424, P<0.001)$ in defaunated animals during the plateau phase ( $\geq 11 \mathrm{wk}$ ).

Compared with that of faunation, the effect sizes of defaunation on total-tract fiber digestibility were linearly 


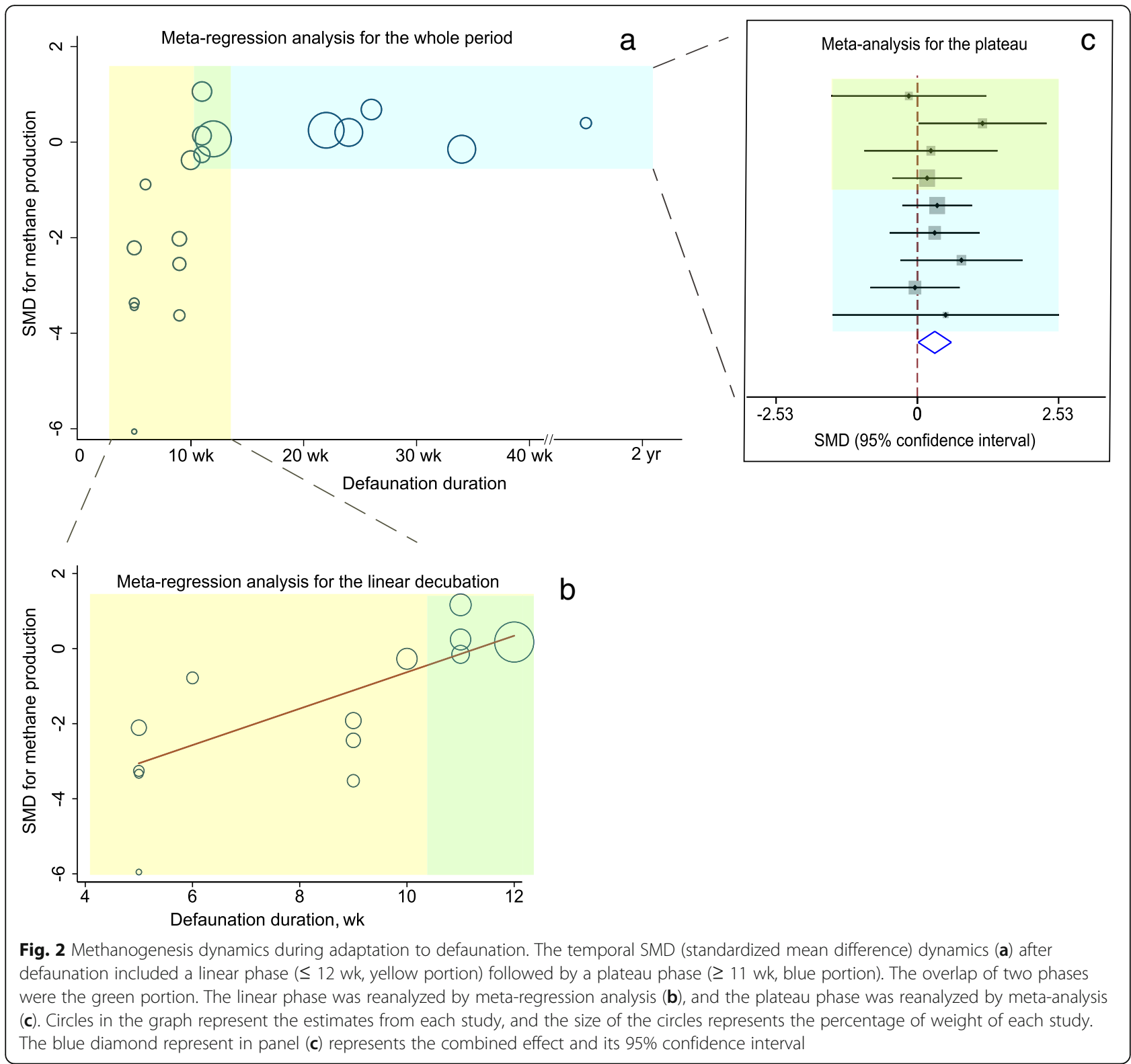

related to defaunation duration (Table 3): total-tract $\mathrm{NDF}$ and ADF digestibility (intercept $=-4.458$ and 6.276, respectively) were reduced $(P<0.01)$ after defaunation, and the reductions decreased weekly $(P<0.05)$ by 0.153 and 0.213 , respectively, until $23 \mathrm{wk}$, which was the longest studied duration in the available data.

\section{Discussion}

\section{Effect size and heterogeneity across all the studies}

Based on all the selected studies, this meta-analysis showed that complete elimination of rumen protozoa generated adverse effects on the ruminal VFA concentration, butyrate proportion and dietary fiber digestibility; these findings were consistent with the results of previous meta-analyses $[14,18]$. However, the heterogeneity across the studies was considerable for most of the responses to defaunation. Excess between-study variance increases the risk of incorrect average effect sizes when combining studies [15]. For example, the present meta-analysis based on all the studies showed that defaunation tended to increase the proportion of ruminal acetate but had no effect on the proportion of propionate. These findings were consistent with a recent meta-analysis by Newbold et al. [18] but inconsistent with that of Eugène et al. [14], who reported that defaunation induced a reduction in the ruminal acetate proportion and an increase in the propionate proportion. Therefore, the potential source of heterogeneity among the studies needs to be explored to better understand the responses to treatment, and this additional exploration is also one of most important tasks of meta-analysis [15]. 


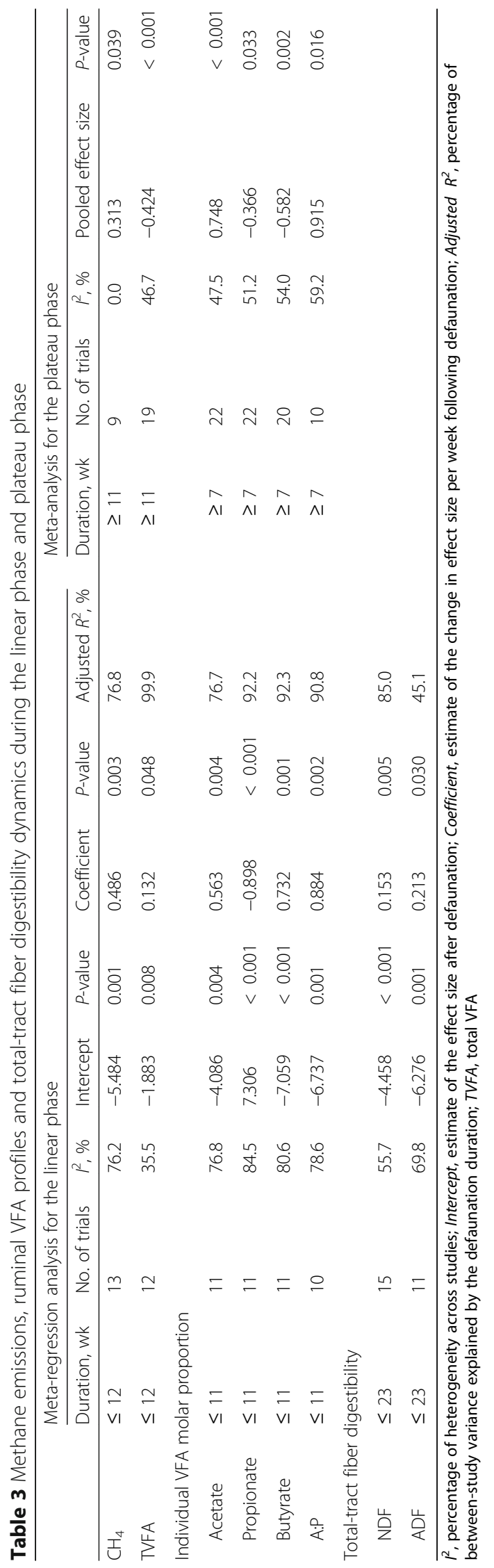


The role of protozoa in rumen carbohydrate metabolism Despite the fact that protozoa make up a large portion of the rumen biomass, their role in ruminal fermentation and their contribution to the metabolism and nutrition of the host are still topics of substantial controversy [2, 14], due to the difficulty of pure cultivation of protozoa in vitro. Rumen protozoa are not essential to the animal for survival, and defaunation has therefore been used to estimate the role of ciliate protozoa in rumen function. However, the adapted alteration of other microbe after defaunation may interfere with such estimations. Hence, the estimated intercept from the meta-regression analysis more accurately reflected the role that protozoa played in rumen fermentation. Reductions in the ruminal acetate proportion, butyrate proportion and $\mathrm{CH}_{4}$ production after complete removal of ruminal protozoa would be expected because protozoa ferment carbohydrates into acetate, butyrate and $\mathrm{H}_{2}$ [2], and the $\mathrm{H}_{2}$ produced is mostly converted to $\mathrm{CH}_{4}$ by methanogens situated inside protozoa or on their external surface [57]. A strong correlation between $\mathrm{CH}_{4}$ emissions and protozoa concentration has been reported [23], and protozoa-associated methanogens have been estimated to be responsible for $37 \%$ of $\mathrm{CH}_{4}$ production by ruminants [5]. Additionally, ruminal protozoa possess a full complement of hydrolytic enzymes for fermentation of the major components of feedstuffs, and certain ciliates present a wide range of fibrolytic enzyme genes, ingest small plant particles and use cell wall carbohydrates [18, 24]. Moreover, protozoa can indirectly contribute to ruminal degradation kinetics by maintaining a suitable rumen fermentation environment, for example, by scavenging oxygen to maintain anaerobiosis and slowing the rate of starch fermentation to maintain a proper ruminal $\mathrm{pH}$ [24], which favors the development and activity of bacteria and fungi $[25,26]$. Therefore, the reductions in dietary fiber digestibility and ruminal total VFA concentration observed in this study would be expected after the complete removal of ruminal protozoa.

\section{Temporal dynamics during adaptation to defaunation}

Although protozoa are important ruminal $\mathrm{H}_{2}$ producers and exhibit interspecies $\mathrm{H}_{2}$ transfer with methanogens, we found that the effects of short- and long-term defaunation on $\mathrm{CH}_{4}$ production were opposite. This finding supports the conclusion of Morgavi et al. [13], who showed that there was not a simple cause-effect relationship between rumen protozoa and methanogenesis. Bird et al. [11] and Hegarty et al. [12] observed higher $\mathrm{CH}_{4}$ production (although not significantly so) in long-term defaunated ewes (11 and $26 \mathrm{wk}$ ) and lambs (12 to 33 wk) than in faunated animals. The significant increasing effect of long-term defaunation on $\mathrm{CH}_{4}$ production detected in this meta-analysis can be attributed to the pooled analysis, in which the number of replicate animals was increased by combining the results of relevant individual studies $[15,16]$. The $\mathrm{CH}_{4}$ emissions from ruminants contribute to global greenhouse gas emissions and represent energy loss for the animals [8, 27, 28]. Therefore, the potential environmental protection and energy-saving values following defaunation were gradually lost and eventually became negative.

Acetate production during rumen fermentation is accompanied by reducing equivalents $([\mathrm{H}])$ production, whereas propionate production is accompanied by $[\mathrm{H}]$ consumption [29]; the excess $[\mathrm{H}]$ is converted to $\mathrm{H}_{2}$. The shift in the VFA profiles from propionate to acetate following defaunation increased the $\mathrm{H}_{2}$ available for methanogenesis, at least partially explaining the time-related changes in $\mathrm{CH}_{4}$ production observed in this study. When glucose is metabolized into acetate, propionate or butyrate, the energy efficiency relative to glucose for animal is $62 \%, 109 \%$ and $78 \%$, respectively [3, 4]. Propionate fermentation is most energy efficient, due to assimilating energy from $\mathrm{H}_{2}$ and being the main precursor of gluconeogenesis in animals [3, 30]. In ruminants, the VFAs produced in the rumen satisfy up to $70 \%$ of energy requirements [30]. Shabat et al. [31] and Weimer et al. [32] observed that the ruminal total VFA concentration and propionate proportion were higher in highly efficient cows than in cows with low efficiency. Therefore, the decreases in the ruminal total VFA concentration and propionate proportion during the plateau phase also suggested that the elimination of rumen protozoa adversely affected the energy supply of animals in a long run.

The time-related variations in $\mathrm{CH}_{4}$, VFA profiles and dietary fiber digestibility implied a series of complex changes in the ruminal ecosystem over the course of defaunation. Nguyen et al. [33] reported that rumen microbes had likely not stabilized after 12 wk of defaunation, which agrees with our results showing that the linear phase for ruminal VFA profiles and $\mathrm{CH}_{4}$ emissions lasted 11 wk and 12 wk, respectively. When sudden major changes are made in the diet, it takes approximately $2 \mathrm{wk}$ for the new microbial population balance to become established [34]; the much longer linear phase associated with defaunation suggests that protozoa play an important role in the ruminal ecosystem. Ruminal methanogens appear to develop more slowly than bacteria following defaunation [13]. Hristov et al. [28] noted that reductions in the population of protozoa-associated methanogens might be compensated by an increase in the population of bacteria- or rumen fluid-associated methanogens, and Mosoni et al. [26] found that long-term defaunation $(2 \mathrm{yr})$ increased the abundance of methanogens. In addition, ruminal protozoa elimination results in increased bacterial abundance and changes in bacterial 
communities [35, 36]; defaunation has been shown to increase the anaerobic fungal population by two fold [37] and the Ruminococcaceae population by six fold [36]. Frumholtz [38] found that long-term defaunation (6 mo) increased the abundance of cellulolytic bacteria. Similar to protozoa, fungi and cellulolytic bacteria are also the main ruminal cellulolytic and $\mathrm{H}_{2}$-producing microbes that generate acetate, butyrate and/or $\mathrm{H}_{2}$ as primary end products $[29,39]$. Therefore, it can be concluded that the increase in the populations of methanogens, fungi and cellulolytic bacteria following defaunation gradually counteracts the defaunation-induced reductions in dietary fiber digestibility, ruminal A:P and $\mathrm{CH}_{4}$ production, which may confirm an earlier theory of Weimer [40] indicating that the multiple microbial taxa in the ruminal community show functional redundancy (overlap of physiological function) and may therefore be substitutable with little impact on ecosystem processes [41, 42]. As noted by Taxis et al. [43] regarding the relationship between ruminal ecosystems and function: the players may change but the game remains. These observations also suggest that defaunation is not a good model for estimating the role of protozoa in rumen function due to the compensation effects of fungi and bacteria. Further animal experiments are required to fully understand the succession of rumen bacterial and archaeal community structure and function following defaunation, and the metabolic characteristics of rumen protozoa need be revealed using their genome and transcriptome data.

\section{Conclusions}

The present meta-analysis summarized the temporal dynamics of methanogenesis, ruminal fermentation and dietary fiber digestibility in ruminants after defaunation, and the results showed that defaunation adversely affected dietary fiber digestibility and the ruminal VFAs available to the host animals, although the effects were lessened over time. Furthermore, the energy advantages of defaunation gained by reducing $\mathrm{CH}_{4}$ production and shifting ruminal VFA profiles to more propionate were gradually lost over time, and the effects eventually became disadvantageous. Therefore, elimination of rumen protozoa adversely affects the energy supply of animals over the long-term.

\section{Additional file}

Additional file 1: Figure S1. Forest plot showing the results of the subgroup meta-analysis of the anti-methanogenic effect size of defaunation, grouped by faunation state and duration of defaunation (11 wk). BF = born and reared protozoa free; $\mathrm{AF}=$ artificial defaunation; $\mathrm{SMD}=$ standardized mean difference; $95 \% \mathrm{Cl}=95 \%$ confidence interval. * I-squared = percentage of heterogeneity across studies; $P$-value of $S M D=0$. Figure S2. Funnel plot for the effect size of defaunation on $\mathrm{CH}_{4}$ production in (A) all studies, (B) short-term defaunation, (C) long-term defaunation, and (D) refaunation. The
$P$-value of publication bias is presented. $\mathrm{SMD}=$ standardized mean difference, se = standard error. (DOCX $1373 \mathrm{~kb})$

\section{Abbreviations}

ADF: Acid detergent fiber; AP: Acetate to propionate ratio; NDF: Neutral detergent fiber; SMD: Standardized mean difference; VFA: Volatile fatty acids

\section{Acknowledgments}

The authors thank Prof. Chang Xu (Chinese Evidence-Based Medicine Center and Chinese Cochrane Center, West China Hospital, Sichuan University) for help with data analysis.

\section{Funding}

This work was supported by the National Key Research and Development Program of China (grant number: 2017YFD0500500).

\section{Availability of data and materials}

All the datasets were presented in the main manuscript (reference list in Table 1) and available to readers.

\section{Authors' contributions}

Conceived and designed the experiments: ZJL, FL and JHY. Performed the experiments: ZJL, QD and YFL. Analyzed the data: ZJL. Contributed to the writing of the manuscript: ZJL, TY and YCC. All authors reviewed and approved the manuscript.

Ethics approval and consent to participate

Not applicable.

\section{Consent for publication}

Not applicable.

\section{Competing interests}

The authors declare that they have no competing interests.

\section{Author details}

${ }^{1}$ College of Animal Science and Technology, Northwest A\&F University, Yangling, Shaanxi, China. ${ }^{2}$ State Key Laboratory of Genetic Resources and Evolution, Kunming Institute of Zoology, Chinese Academy of Sciences, Kunming, Yunnan, China. ${ }^{3}$ College of Pastoral Agricultural Science and Technology, Lanzhou University, Lanzhou, China.

Received: 5 July 2018 Accepted: 5 November 2018

Published online: 18 December 2018

\section{References}

1. Ushida K, Jouany JP, Demeyer DI. Effects of presence or absence of rumen protozoa on the efficiency of utilization of concentrate and fibrous feeds. In: Tsuda T, Sasaki Y, Kawashima, editors. Physiological aspects of digestion and metabolism in ruminants. San Diego: Academic Press. 1991:625-54.

2. Williams AG, Coleman GS. The rumen protozoa. 1st ed. New York: SpringerVerlag; 1992.

3. Millen DD, Arrigoni MDB, Pacheco RDL. Rumenology. 1st ed. Springer: International Publishing; 2016.

4. Ryle M, Ørskov ER. Energy nutrition in ruminants. 1st ed. Netherlands: Springer; 1990.

5. Finlay BJ, Esteban G, Clarke KJ, Williams AG, Embley TM, Hirt RP. Some rumen ciliates have endosymbiotic methanogens. FEMS Microbiol Lett. 1994;117:157-61.

6. Morgavi DP, Forano E, Martin C, Newbold CJ. Microbial ecosystem and methanogenesis in ruminants. Animal. 2010;4:1024-36.

7. Belanche A, de la Fuente G, Newbold CJ. Study of methanogen communities associated with different rumen protozoal populations. FEMS Microbiol Ecol. 2014;90:663-77.

8. Johnson KA, Johnson DE. Methane emissions from cattle. J Anim Sci. 1995; 73:2483-92.

9. Whitelaw FG, Eadie JM, Bruce LA, Shand WJ. Methane formation in faunated and ciliate-free cattle and its relationship with rumen volatile fatty acid proportions. Br J Nutr. 1984;52:261-75. 
10. Faichney GJ, Graham NM, Walker DM. Rumen characteristics, methane emissions, and digestion in weaned lambs reared in isolation. Aust J Agric Res. 1999;50:1083-90.

11. Bird SH, Hegarty RS, Woodgate R. Persistence of defaunation effects on digestion and methane production in ewes. Aust J Exp Agric. 2008;48:152-5.

12. Hegarty RS, Bird SH, Vanselow BA, Woodgate R. Effects of the absence of protozoa from birth or from weaning on the growth and methane production of lambs. Br J Nutr. 2008;100:1220-7.

13. Morgavi DP, Martin C, Jouany JP, Ranilla MJ. Rumen protozoa and methanogenesis: not a simple cause-effect relationship. Br J Nutr. 2012;107:388-97.

14. Eugène $M$, Archimède $H$, Sauvant $D$. Quantitative meta-analysis on the effects of defaunation of the rumen on growth, intake and digestion in ruminants. Livest Prod Sci. 2004;85:81-97.

15. Lean IJ, Rabiee AR, Duffield TF, Dohoo IR. Invited review: use of metaanalysis in animal health and reproduction: methods and applications. J Dairy Sci. 2009;92:3545-65.

16. Viechtbauer W. Learning from the past: refining the way we study treatments. J Clin Epidemiol. 2010;63:980-2.

17. Newbold CJ, de la Fuente G, Belanche A, Ramos-Morales E, McEwan NR. The role of ciliate protozoa in the rumen. Front Microbiol. 2015;6:1313.

18. Sauer FD, Fellner V, Kinsman R, Kramer JK, Jackson HA, Lee AJ, et al. Methane output and lactation response in Holstein cattle with monensin or unsaturated fat added to the diet. J Anim Sci. 1998;76:906-14.

19. Guan $H$, Wittenberg KM, Ominski KH, Krause DO. Efficacy of ionophores in cattle diets for mitigation of enteric methane. J Anim Sci. 2006;84:1896-906.

20. Schönhusen U, Zitnan R, Kuhla S, Jentsch W, Derno M, Voigt J. Effects of protozoa on methane production in rumen and hindgut of calves around time of weaning. Arch Anim Nutr. 2003:57:279-95.

21. Higgins JPT, Thompson SG, Deeks JJ, Altman DG. Measuring inconsistency in meta-analyses. BMJ. 2003;327:557-60.

22. Knapp G, Hartung J. Improved tests for a random effects meta-regression with a single covariate. Stat Med. 2003:22:2693-710.

23. Guyader J, Eugène $M$, Nozière $P$, Morgavi DP, Doreau M, Martin C. Influence of rumen protozoa on methane emission in ruminants: a meta-analysis approach. Animal. 2014;8:1816-25.

24. Nagaraja TG. Microbiology of the rumen. In: Millen DD, Arrigoni MDB, Pacheco RDL, editors. Rumenology. Cham: Springer; 2016. p. 39-61.

25. Jouany JP, Demeyer DI, Grain J. Effect of defaunating the rumen. Anim Feed Sci Technol. 1988;21:229-65.

26. Mosoni P, Martin C, Forano E, Morgavi DP. Long-term defaunation increases the abundance of cellulolytic ruminococci and methanogens but does not affect the bacterial and methanogen diversity in the rumen of sheep. J Anim Sci. 2011;89:783-91.

27. Karakurt I, Aydin G, Aydiner K. Sources and mitigation of methane emissions by sectors: a critical review. Renew Energy. 2012;39:40-8.

28. Hristov AN, Oh J, Lee C, Meinen R. Mitigation of greenhouse gas emissions in livestock production: a review of technical options for non- $\mathrm{CO}_{2}$ emissions. Food and Agriculture Organization of the United Nations: Rome; 2013.

29. Janssen PH. Influence of hydrogen on rumen methane formation and fermentation balances through microbial growth kinetics and fermentation thermodynamics. Anim Feed Sci Technol. 2010:160:1-22.

30. Bergman EN. Energy contributions of volatile fatty acids from the gastrointestinal tract in various species. Physiol Rev. 1990;70:567-90.

31. Shabat SKB, Sasson G, Doron-Faigenboim A, Durman T, Yaacoby S, Berg Miller ME, et al. Specific microbiome-dependent mechanisms underlie the energy harvest efficiency of ruminants. ISME J. 2016. https://doi.org/10.1038/ismej.2016.62.

32. Weimer PJ, Cox MS, de Paula TV, Lin M, Hall MB, Suen G. Transient changes in milk production efficiency and bacterial community composition resulting from near-total exchange of ruminal contents between high- and low-efficiency Holstein cows. J Dairy Sci. 2017;100:7165-82.

33. Nguyen SH, Bremner G, Cameron M, Hegarty RS. Methane emissions, ruminal characteristics and nitrogen utilisation changes after refaunation of protozoa-free sheep. Small Rumin Res. 2016;144:48-55.

34. Reece WO. Dukes' physiology of domestic animals. 12th ed. Comstock Pub. Associates: Ithaca; 2004.

35. Ozutsumi $Y$, Tajima $K$, Takenaka A, Itabashi $H$. The effect of protozoa on the composition of rumen bacteria in cattle using $16 \mathrm{~S}$ rRNA gene clone libraries. Biosci Biotechnol Biochem. 2005:69:499-506.

36. Morgavi DP, Rathahao-Paris E, Popova M, Boccard J, Nielsen KF, Boudra H. Rumen microbial communities influence metabolic phenotypes in lambs. Front Microbiol. 2015;6:1060.
37. Newbold CJ, Hillman K. The effect of ciliate protozoa on the turnover of bacterial and fungal protien in the rumen of sheep. Lett Appl Microbiol. 1990;11:100-2.

38. Frumholtz PP. Manipulation of the rumen fermentation and its effects on digestive physiology: University of Aberdeen; 1991.

39. Morvan B, Rieu-Lesme F, Fonty G, Gouet P. In vitro interactions between rumen $\mathrm{H}_{2}$-producing cellulolytic microorganisms and $\mathrm{H}_{2}$-utilizing acetogenic and sulfate-reducing bacteria. Anaerobe. 1996;2:175-80.

40. Weimer PJ. Redundancy, resilience, and host specificity of the ruminal microbiota: implications for engineering improved ruminal fermentations. Front Microbiol. 2015:6:296.

41. Lawton JH, Brown VK. Redundancy in ecosystems. In: Schulze ED, Mooney HA, editors. Biodiversity and ecosystem function. Berlin: Springer; 1994. p. 255-70.

42. Rosenfeld JS. Functional redundancy in ecology and conservation. Oikos. 2002;98:156-62.

43. Taxis TM, Wolff S, Gregg SJ, Minton NO, Zhang C, Dai J, et al. The players may change but the game remains: network analyses of ruminal microbiomes suggest taxonomic differences mask functional similarity. Nucleic Acids Res. 2015. https://doi.org/10.1093/nar/gkv973.

44. Belanche A, Abecia L, Holtrop G, Guada JA, Castrillo C, de la Fuente G, et al. Study of the effect of presence or absence of protozoa on rumen fermentation and microbial protein contribution to the chyme. J Anim Sci. 2011:89:4163-74.

45. Chandramoni JSB, Tiwari CM, Haque N, Murarilal KMY. Energy metabolism and methane production in faunated and defaunated sheep fed two diets with same concentrate to roughage ratio $(70: 30)$ but varying in composition. Asian-Australas J Anim Sci. 2001;14:1238-44.

46. Chaudhary LC, Srivastava A. Performance of growing Murrah buffalo calves as affected by treatment with Manoxol and the presence of ciliate protozoa in the rumen. Anim Feed Sci Technol. 1995:51:281-6.

47. Eadie JM, Gill JC. The effect of the absence of rumen ciliate protozoa on growing lambs fed on a roughage-concentrate diet. Br J Nutr. 1971;26:155-67.

48. Eugène $M$, Sauvant $D$, Weisbecker $J$, Archimède $H$. Effects of defaunation on digestion of fresh Digitaria decumbens grass and growth of lambs. Animal. 2010;4:439-45

49. Kasuya N, Wada I, Shimada M, Kawai H, Itabashi H. Effect of presence of rumen protozoa on degradation of cell wall constituents in gastrointestinal tract of cattle. Anim Sci J. 2007;78:275-80.

50. Kreuzer M, Kirchgessner M, Müller HL. Effect of defaunation on the loss of energy in wethers fed different quantities of cellulose and normal or steamflaked maize starch. Anim Feed Sci Technol. 1986:16:233-41.

51. Nagaraja TG, Godfrey SI, Winslow SW, Rowe JB, Kemp KE. Effect of virginiamycin on ruminal fermentation in faunated or ciliate-free sheep overfed with barley grain. Small Rumin Res. 1995;17:1-8.

52. Santra A, Karim SA. Growth performance of faunated and defaunated Malpura weaner lambs. Anim Feed Sci Technol. 2000;86:251-60.

53. Santra A, Karim SA. Nutrient utilization and growth performance of defaunated and faunated lambs maintained on complete diets containing varying proportion of roughage and concentrate. Anim Feed Sci Technol. 2002;101:87-99.

54. Santra A, Karim SA, Chaturvedi $\mathrm{OH}$. Rumen enzyme profile and fermentation characteristics in sheep as affected by treatment with sodium lauryl sulfate as defaunating agent and presence of ciliate protozoa. Small Rumin Res. 2007:67:126-37

55. Sultana H, Miyazawa K, Kanda S, Itabashi H. Fatty acid composition of ruminal bacteria and protozoa, and effect of defaunation on fatty acid profile in the rumen with special reference to conjugated linoleic acid in cattle. Anim Sci J. 2011;82:434-40

56. Williams PP, Dinusson WE. Ruminal volatile fatty acid concentrations and weight gains of calves reared with and without ruminal ciliated protozoa. J Anim Sci. 1973:36:588-91.

57. Yáñez-Ruiz DR, Williams S, Newbold CJ. The effect of absence of protozoa on rumen biohydrogenation and the fatty acid composition of lamb muscle. Br J Nutr. 2007:97:938-48.

58. Zhou YY, Mao HL, Jiang F, Wang JK, Liu JX, McSweeney CS. Inhibition of rumen methanogenesis by tea saponins with reference to fermentation pattern and microbial communities in Hu sheep. Anim Feed Sci Technol. 2011:166-167:93-100. 